\title{
Outcomes and Prognostic Factors of Small Cell Lung Cancer: A Retrospective Study
}

\author{
Hanan Ahmed Wahba', Hend Ahmed El-Hadaad1 ${ }^{*}$, Abeer Hussein Anter ${ }^{1}$, \\ Magda Abdel-Salam Ahmad², Hayam Fathy Abd-El Hay Ghazy ${ }^{3}$ \\ ${ }^{1}$ Clinical Oncology \& Nuclear Medicine Department, Mansoura University Hospital, Faculty of Medicine, Mansoura, Egypt \\ ${ }^{2}$ Chest Medicine Department, Mansoura University Hospital, Faculty of Medicine, Mansoura, Egypt \\ ${ }^{3}$ Medical Oncology Department, Mansoura Oncology Center, Faculty of Medicine, Mansoura, Egypt \\ Email: ^hend_am@mans.edu.eg
}

How to cite this paper: Hanan Ahmed, H., El-Hadaad, H.A., Anter, A.H., Ahmad, M.A.-S. and Abd-El Hay Ghazy, H.F. (2018) Outcomes and Prognostic Factors of Small Cell Lung Cancer: A Retrospective Study. Advances in Lung Cancer, 7, 21-31. https://doi.org/10.4236/alc.2018.73003

Received: August 18, 2018

Accepted: September 27, 2018

Published: September 30, 2018

Copyright (ㅇ 2018 by authors and Scientific Research Publishing Inc. This work is licensed under the Creative Commons Attribution International License (CC BY 4.0).

http://creativecommons.org/licenses/by/4.0/

(c) (i) Open Access

\begin{abstract}
Background: Small cell lung cancer (SCLC) is a high grade neuroendocrine tumor, and has aggressive nature, so the majority of cases are presented with extensive disease. SCLC was staged into 2 categories: limited-stage disease (LS-SCLC) and extensive disease (ES-SCLC). Despite SCLC is sensitive to radiotherapy and chemotherapy, SCLC has high tendency for rapid dissemination to regional and distant sites. Median survival time ranged from $2-4$ months in patients with untreated SCLC. Multiagent chemotherapy was the primary treatment for SCLC. Aim of the work: This retrospective study was conducted to evaluate and analyze clinical features, treatment outcome, survival and prognostic factors affecting survival in patients with SCLC presented to Clinical Oncology and Nuclear Medicine department, Chest department and Medical oncology unit in Mansoura Oncology Centre during the period from 2000-2015. Methods: Data of patients were collected from their files. The information obtained included demographic features, treatment received; its toxicity and outcome, survival and its prognostic factors. Demographic data were: age, Eastern Cooperative Oncology Group Performance Status (ECOG-PS), smoking status, stage of disease. Data also included disease presentation and metastatic sites. Several factors affecting survival were analysed as age, sex, stage, PS, smoking status and LDH. Results: Sixty-three patients were enrolled in this study. Median age was $56.2 \pm 6$. Strong male predominance $(92.1 \%)$ was observed; $84.1 \%$ of them were smoker. Thirty six patients (57.2\%) were of ECOG-PS of 0 - 1. ES-SCLC was reported in $65 \%$ of cases and $\mathrm{LDH}$ was high $(>1.5 \mathrm{xN})$ in $47.6 \%$. The most common symptom was chest pain (38.1\%) followed by cough (31.8\%), weight loss $(30 \%)$. Fifteen patients had single metastatic site $(23.8 \%)$ and bone was
\end{abstract}


the most common site of metastasis (reported in 8 patients) followed by brain, lung and liver. 2 -year overall survival rate was $35 \%$ with median survival time of 14 months. On multivariate analysis, there were significantly higher survival in patients aged $<65$ years $(\mathrm{P}=0.03)$, female gender $(\mathrm{P}=$ 0.04), LD-SCLC $(P=0.03)$, good performance status $(P=0.04)$, low LDH level $(\mathrm{P}=0.02)$ and non-smoker $(\mathrm{P}=0.04)$. Conclusion: This clinico-epidemiologic study provides multiple prognostic factors that have important impact on survival as age, sex, LDH level, stage, smoking and performance status. Larger number of patients and prospective studies are needed to clarify more prognostic factor.

\section{Keywords}

SCLC, Lung Cancer, LS-SCLC, ES-SCLC

\section{Introduction}

In both men and women, lung cancer is the most common malignancy and accounts for $18 \%$ of deaths worldwide [1]. There are 2 different pathological types of lung cancer: small cell lung cancer (SCLC) and non-small cell lung cancer (NSCLC). The prevalence of SCLC is $15 \%-20 \%$ and associated with cigarette smoking [2]. SCLC is a high grade neuroendocrine tumor, has aggressive nature. So the majority of cases are presented by extensive disease [3]. SCLC was staged into 2 categories: limited-stage disease (LS-SCLC) and extensive disease (ES-SCLC). LS-SCLC is confined to one hemithorax, regional mediastinal lymph nodes and ipsilateral supraclavicular lymph nodes [4]. When patients have disease spread beyond supraclavicular areas, they are classified as ES-SCLC [5]. Despite SCLC is sensitive to radiotherapy and chemotherapy, SCLC has high tendency for rapid dissemination to regional and distant sites [6]. Median survival time ranged from 2 - 4 months in patients with untreated SCLC [7]. Multiagent chemotherapy was the primary treatment for SCLC [8]. Because of recurrence at disease site in LS-SCLC, thoracic radiotherapy (TRT) was added to decrease intrathoracic failure [9]. Arriagada et al. [10] reported 3-year survival rate of 8.9\% with chemotherapy alone versus $14.3 \%$ with chemoradiotherapy. For ES-SCLC combined chemotherapy is the standard treatment and radiotherapy is recommended to cure metastasis or to relieve pain [11] [12]. However, addition of TRT in some patients was suggested as it was found to improve overall survival [13] [14]. Brain is the most common site for distant failure and associated with poor survival ranged from 4 - 6 months only [15] [16]. So in SCLC, prophylactic cranial irradiation (PCI) has been established for patients with complete or partial response to chemotherapy [17] [18] [19].

This retrospective study was conducted to evaluate and analyze clinical features, treatment outcome, survival and prognostic factors affecting survival in patients with SCLC. 


\section{Patients and Methods}

Medical records of all patients with SCLC presented to Clinical Oncology and Nuclear Medicine department, Chest department and Medical oncology unit in Mansoura Oncology Centre, Mansoura University during the period from 2000-2015 were reviewed.

Data of patients were collected from their files. The information obtained included demographic features, treatment received; its toxicity and outcome, survival and its prognostic factors.

Demographic data were: age, Eastern Cooperative Oncology Group Performance Status (ECOG-PS), smoking status, stage of disease. Data also included disease presentation and metastatic sites.

Patients were evaluated through history, physical examination, radiological and laboratory findings and pathological diagnosis.

Radiological investigations were computed tomography (CT) or magnetic resonance imaging (MRI) of the chest, abdomen and brain and radionuclide bone imaging. Laboratory tests included complete blood picture, liver and kidney function tests, lactic dehydrogenase (LDH). Bone marrow aspirate and biopsy were indicated if there was pancytopenia or high level of LDH. Any detected effusion on chest radiography was evaluated through cytological examination.

Toxic effects of treatment were assessed using the National Cancer Institute Common Toxicity Criteria (NCI-CTC) V3.0.

Response to treatment was assessed through Response Evaluation Criteria in Solid Tumors (RECIST) [20].

During follow-up period; all investigations were repeated every 3 months for 2 years then every 6 months thereafter.

Overall survival (OAS) was calculated from date of pathological diagnosis to date of death or last follow-up.

Several factors affect survival were analysed as age, sex, stage, PS, smoking status and LDH.

Statistical methods: IBM SPSS was used for statistical analysis, data expressed as number and percentile, Chi square test used as a test of significance, $\mathrm{P}<0.05$ considered significant. Kaplan-Meier test was used for survival function.

Ethical consideration: This study was approved by the Medical Ethics Committee.

\section{Results}

Sixty-three patients were enrolled in this retrospective study. Their demographic features are summarized in Table 1. Median age was $56.2 \pm 6$. There were strong male predominance $(92.1 \%)$ and $84.1 \%$ of them were smoker. Performance status of the patients was not very poor as 36 patients (57.2\%) were of ECOG-PS of $0-1$, ES-SCLC was reported in $65 \%$ of cases and LDH was high $(>1.5 \mathrm{xN})$ in $47.6 \%$.

The most frequent symptom was chest pain (38.1\%) followed by cough (31.8\%), weight loss (30\%) (Table 2).

Fifteen patients had single metastatic site (23.8\%). Bone was the most common 
Table 1. Demographic features.

\begin{tabular}{ccc}
\hline character & N & $\%$ \\
\hline Age & & \\
Median (range): $56.2 \pm 6$ & & \\
$(32-78)$ years & & 92.1 \\
Gender & 58 & 7.9 \\
Male & 5 & \\
Female & & 84.1 \\
Smoking status & 53 & 15.9 \\
Yes & 10 & \\
No & & 17.5 \\
ECOG-PS & 11 & 39.7 \\
0 & 25 & 33.3 \\
1 & 21 & 9.5 \\
2 & 6 & \\
3 & & 65.9 \\
Stage & 22 & 52.4 \\
LD-SCLC & 41 & 47.6 \\
ES-SCLC & & \\
LDH & 33 & \\
Normal & 30 & \\
High & & \\
& &
\end{tabular}

Table 2. Presenting symptom.

\begin{tabular}{cc}
\hline Symptom & $\mathrm{N}(\%)$ \\
\hline Chest pain & $24(38.1)$ \\
Cough & $20(31.8)$ \\
Weight loss & $19(30.2)$ \\
Dyspnea & $15(23.8)$ \\
Hoarsness & $8(12.7)$ \\
Bone ache & $7(11.1)$ \\
Hemoptysis & $5(7.9)$ \\
\hline
\end{tabular}

site of metastasis as reported in 8 patients followed by brain, lung and liver as shown in Table 3.

EP chemotherapy regimen was used in all patients, consisted of cisplatin 80 $\mathrm{mg} / \mathrm{m}^{2}$ day 1 i.v and $100 \mathrm{mg} / \mathrm{m}^{2}$ of etoposide days $1-3$ i.v; cycle was repeated every 3 weeks. After failure of EP, 15 patients needed other regimen of CAV that consisted of cyclophosphamide $1000 \mathrm{mg} / \mathrm{m}^{2} \mathrm{~d} 1 \mathrm{i} . \mathrm{v}$, adriamycin $45 \mathrm{mg} / \mathrm{m}^{2} \mathrm{~d} 1 \mathrm{i} . \mathrm{v}$ and vincristine $1 \mathrm{mg} / \mathrm{m}^{2} \mathrm{~d} 1$ i.v to be repeated every 3 weeks while 3 patients with poor general condition after EP, received supportive care.

Patients with LD-SCLC received either concurrent chemoradiotherapy in 9 patients $(40.9 \%)$ or sequential treatment of chemotherapy then radiotherapy in 13 patients (59.1\%). Response rate was $36.5 \%$ with complete response in $12.7 \%$ while disease progression found in $28.6 \%$ (Table 4). As shown in Table 5; 
Table 3. Metastatic sites.

\begin{tabular}{cc}
\hline Site & $\mathrm{N}(\%)$ \\
\hline One site & $15(23.8)$ \\
$\geq 2$ sites & $7(11.1)$ \\
Bone & $8(12.6)$ \\
Brain & $5(7.9)$ \\
Lung & $4(6.3)$ \\
Liver & $2(3.2)$ \\
\hline
\end{tabular}

Table 4. Response rate.

\begin{tabular}{cc}
\hline Response rate & N (\%) \\
\hline Complete response (CR) & $8(12.7)$ \\
Partial (PR) & $15(23.8)$ \\
Stable disease (SD) & $22(34.9)$ \\
Progressive disease (PD) & $18(28.6)$
\end{tabular}

Table 5. Acute toxicity treatment.

\begin{tabular}{cccc}
\hline \multirow{2}{*}{ Toxicity } & \multicolumn{3}{c}{ Grade } \\
\cline { 2 - 4 } & \multicolumn{1}{c}{ } & 3 & $\mathrm{~N}(\%)$ \\
\cline { 2 - 4 } Leukopenia & $18(28.6)$ & $\mathrm{N}(\%)$ & $2(3.2)$ \\
Thrombocytopenia & $15(23.8)$ & $6(9.5)$ & $1(1.6)$ \\
Anemia & $11(17.5)$ & $5(7.9)$ & $1(1.6)$ \\
Nausea/vomiting & $22(34.9)$ & $8(12.7)$ & 0 \\
Esophagitis & $10(15.9)$ & $5(7.9)$ & 0 \\
Pneumonitis & $7(11.1)$ & $3(4.8)$ & 0 \\
\hline
\end{tabular}

leucopenia was the most frequent hematologic toxicity with >grade I in $41.3 \%$ followed by thrompocytopenia. Nausea and vomiting $>$ grade I was found in $47.6 \%$ as the most common non hematologic toxicity. No reported grade IV toxicity in non hematologic one but reported in $6.4 \%$ of hematologic toxicity.

2 -year overall survival rate was $35 \%$ with median survival time of 14 months (Figure 1).

On multivariate analysis; we found significantly higher survival in patients aged $<65$ years $(P=0.03)$, female gender $(P=0.04)$, LD-SCLC $(P=0.03)$, good performance status $(\mathrm{P}=0.04)$, low LDH level $(\mathrm{P}=0.02)$ and non-smoker $(\mathrm{P}=$ $0.04)$.

\section{Discussion}

Although treatment of lung cancer has much progress, it is still the leading cause of cancer-associated mortality all over the world [21]. 


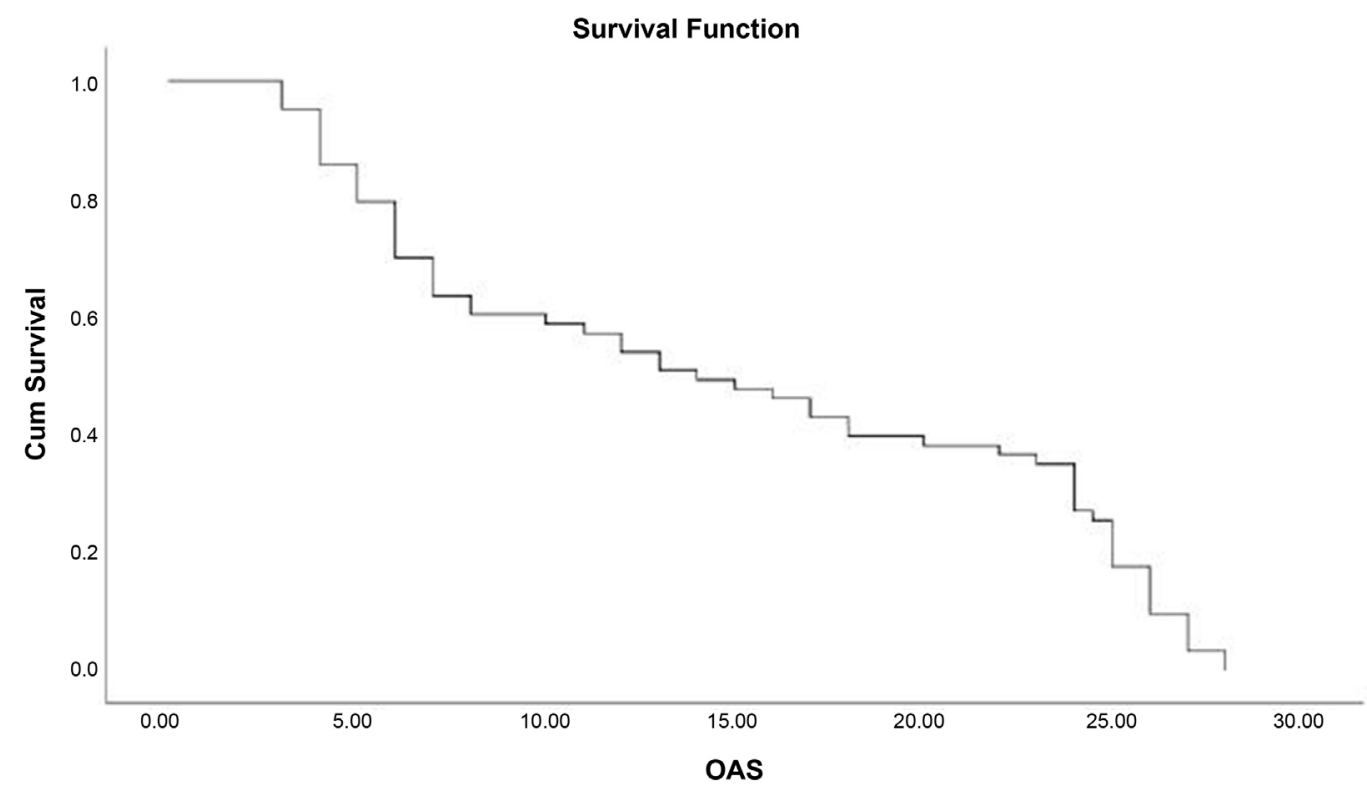

Figure 1. Over all survival of patients in months.

In our population study, median age was $56 \pm 6$ that is similar to literature [22] [23]. As expected $84 \%$ of our patients were smokers. It was reported that smoking is the most serious etiology of lung cancer but also current smoking during treatment compromise survival [24] [25].

Males are more smoker than females in our locality; this may explain the more prevalence of SCLC in males.

Multiple features are associated with lung cancer either due to: 1) local disease as chest pain, cough or local spread as hoarseness of voice 2) distant spread as bone ache and weight loss which is a symptom of systemic disease [26]. In our study chest pain was the most frequent complaint followed by cough and weight loss.

Disease was limited in $35 \%$ and extensive in $65 \%$ comparable to other studies that reported higher incidence of extensive disease [3] [27].

In our patients, about $24 \%$ were presented by single site of metastasis while $11 \%$ had $\geq 2$ sites and bone was the most common site of metastasis followed by brain similar to what reported by Luan et al. [28]. However, others found that the frequency of metastatic sites were liver then brain and bone [29] [30].

All our patients received EP regimen.

In the European Society for Medical Oncology (ESMO) guidelines patients with small cell lung cancer are advised to receive chemotherapy of cisplatin or carboplatin-based regimen [31].

Although EP is the most widely used regimen; in a randomized trial IP combination (irinotecan-cisplatin) was superior to EP as regard survival rates [32]. However, it was found that IP cause increased gastrointestinal toxicity [33].

Nine patients with limited disease received concurrent chemoradiotherapy which has the advantages of shorter overall treatment time and increase treat- 
ment intensity due to synergism between both therapy but it has the disadvantages of increased toxicity [34]. In our study, leucopenia was the most prevalent hematologic toxicity (41.3\%) while esophagitis (23.8\%) followed by pneumonitis (15.9\%) were the most frequent non hematologic one. But Luanz reported incidence of pneumonitis and esophagitis of $1.8 \%$ and $1.2 \%$ respectively [28]. This can be explained by using 3D conformal TRT for all his patients while only $7.6 \%$ of our group treated by 3D conformal TRT. As regard prognostic factors for survival; ECOG of $0-1$ was associated with significantly higher survival $(\mathrm{P}=$ 0.04) comparable to that recorded by Nathan $\mathrm{R}$ et al. [35] who explained that by receiving more often full dose therapy in patients with ECOG 0 - 1 than those with $\mathrm{ECOG} \geq 2$.

High level of LDH was associated with significantly worse prognosis $(\mathrm{P}=$ 0.02) consistent with other studies [36] [37]. Smoking was a negative prognostic factor. The mechanism of this finding is unclear. It was found that nicotine protects cancer cells from apoptosis induced by many factors as chemotherapeutic agents, tumor necrosis factors [38] [39]. Studies suggest nicotine possesses angiogenic activities and promote cell migration and invasion [40] [41] [42]. Although Videtic et al. [25] and Chen J et al. [43] showed that continuation of smoking during treatment causes poorer survival rates; Bergnar and Sorenson [44] found no survival difference.

In our study age, male gender and extensive stage disease are poor prognostic factors. That is similar to that encountered in some studies [45] [46] [47] but others not found old age as an adverse prognostic factor [48] [49]. They observed that when older patients with good performance status receive multimodality treatment as younger had the same survival.

2 -year survival rate $35 \%$ with median overall survival time of 14 months comparable to what reported by Luan Z et al. [28] and Unalmis et al. [29]. While Ramlov A et al. [50] recorded higher median survival time which can be attributed to higher percentage of patients with LD-SCLC in their study (62.7\%).

For LD-SCLC; it was found that concurrent chemoradiotherapy with $50 \mathrm{~Gy}$ and overdoses radiotherapy provide improvement in overall survival [51]. It was concluded that when radiotherapy started within 30 days of chemotherapy provide better survival rates than if started $>30$ days after chemotherapy [52].

\section{Conclusion}

This clinic-epidemiologic study provides multiple prognostic factors that have important impact on survival as age, sex, LDH level, stage, smoking and performance status. Larger number of patients and prospective studies are needed to clarify more prognostic factors.

\section{Conflicts of Interest}

The authors declare no conflicts of interest regarding the publication of this paper. 


\section{References}

[1] Jemal, A., Bray, F., Center, M.M., et al. (2011) Global Cancer Statistics. CA: A Cancer Journal for Clinicians, 61, 69-90. https://doi.org/10.3322/caac.20107

[2] Jett, J.R., Schild, S.E., Kesler, K.A., et al. (2013) Treatment of Small Cell Lung Cancer: Diagnosis and Management of Lung Cancer, 3rd Ed: American College of Chest Physicians Evidence-Based Clinical Practice Guidelines. Chest, 143, e400S-e419S.

[3] Halperin, C.E., Wazer, D.E., Carlos, A.P., et al. (2013) Perez and Brady's Principles and Rdiation Oncology. 6th Edition, Lippincott Wiliams and Wilkins, Philadelphia, $966 \mathrm{p}$.

[4] Murray, N., Copy, P., Pater, J.L., et al. (1993) Importance of Timing for Thoracic Irradiation in the Combined Modality Treatment of Limited-Stage Small Cell Lung Cancer. The National Cancer Institute of Canada Clinical Trials Group. Journal of Clinical Oncology, 11, 336-344. https://doi.org/10.1200/JCO.1993.11.2.336

[5] Simon, G.R. and Turrisi, A. (2007) American College of Chest Physicians. Management of Small Cell Lung Cancer: ACCP Evidence-Based Clinical Practice Guidelines (2nd Edition). Chest, 132, 324S-339S. https://www.sciencedirect.com/science/article/pii/S001236921535529X

[6] Socinski, M.A., Smit, E.F., Lorigan, P., et al. (2009) Phase III Study of Pemetrexed plus Carboplatin Compared with Etoposide plus Carboplatin in Chemotherapy-Naive Patients with Extensive-Stage Small-Cell Lung Cancer. Journal of Clinical Oncology, 27, 4787-4792. https://doi.org/10.1200/JCO.2009.23.1548

[7] Simon, G.R. and Wagner, H. (2003) American College of Chest Physicians. Small cell Lung Cancer. Chest, 123, 2571S. https://doi.org/10.1378/chest.123.1_suppl.259S

[8] Souhami, R.L., Geddes, D.M., Spiro, S.G., et al. (1984) Radiotherapy in Small Cell Cancer of the Lung Treated with Combination Chemotherapy: A Controlled Trial. British Medical Journal (Clinical Research Ed.), 288, 1643-1646. https://doi.org/10.1136/bmj.288.6431.1643

[9] Warde, P. and Payne, D. (1992) Does Thoracic Irradiation Improve Survival and Local Control in Limited-Stage Small-Cell Carcinoma of the Lung? A Meta-Analysis. Journal of Clinical Oncology, 10, 890-895. https://doi.org/10.1200/JCO.1992.10.6.890

[10] Arriagada, R., Pignon, J.P., Ihde, D.C., et al. (1994) Effect of Thoracic Radiotherapy on Mortality in Limited Small Cell Lung Cancer. A Meta Analysis of 13 Randomized Trials among 2,140 Patients. Anticancer Research, 14, 333-335.

[11] Kallianos, A., Rapti, A., Zarogoulidis, P., et al. (2013) Therapeutic Procedure in Small Cell Lung Cancer. Journal of Thoracic Disease, 5, S420-S424.

[12] Ganti, A.K., West, W.W. and Zhen, W. (2013) Current Concepts in the Management of Small Cell Lung Cancer. Indian Journal of Medical Research, 137, 1043-1051.

[13] Zhu, H., Zhou, Z., Wang, Y., et al. (2011) Thoracic Radiation Therapy Improves the Overall Survival of Patients with Extensive-Stage Small Cell Lung Cancer with Distant Metastasis. Cancer, 117, 5423-5431. https://doi.org/10.1002/cncr.26206

[14] Yee, D., Butts, C., Reiman, A., et al. (2012) Clinical Trial of Post-Chemotherapy Consolidation Thoracic Radiotherapy for Extensive-Stage Small Cell Lung Cancer. Radiotherapy and Oncology, 102, 234-238. https://doi.org/10.1016/j.radonc.2011.08.042

[15] Socha, J. and Kepka, L. (2012) Prophylactic Cranial Irradiation for Small-Cell Lung 
Cancer: How, When and Whom? Expert Review of Anticancer Therapy, 12, 505-517. https://doi.org/10.1586/era.12.19

[16] Seute, T., Leffers, P., Ten Velde, G.P., et al. (2004) Neurologic Disorders in 432 Consecutive Patients with Small Cell Lung Carcinoma. Cancer, 100, 801-806. https://doi.org/10.1002/cncr.20043

[17] Patel, S., Macdonald, O.K. and Suntharalingam, M. (2009) Evaluation of the Use of Prophylactic Cranial Irradiation in Small Cell Lung Cancer. The Cancer, 115, 842-850. https://doi.org/10.1002/cncr.24105

[18] Slotman, B., Faivre-Finn, C., Kramer, G., et al. (2007) Prophylactic Cranial Irradiation in Extensive-Stage Small Cell Lung Cancer. The New England Journal of Medicine, 357, 664-672. https://doi.org/10.1056/NEJMoa071780

[19] Schild, S.E., Foster, N.R., Meyers, J.P., et al. (2012) Prophylactic Cranial Irradiation in Small-Cell Lung Cancer: Findings from a North Central Cancer Treatment Group Pooled Analysis. Annals of Oncology, 23, 2919-2924. https://doi.org/10.1093/annonc/mds123

[20] Eisenhauer, E.A., Therasse, P., Bogaerts, J., et al. (2009) New Response Evaluation Criteria in Solid Tumors: Revised RECIST Guideline (Version 1.1). European Journal of Cancer, 45, 228-247. https://doi.org/10.1016/j.ejca.2008.10.026

[21] Siegel, R., Naishadham, D. and Jemal, A. (2013) Cancer Statistics, 2013. CA: $A$ Cancer Journal for Clinicians, 63, 11-30. https://doi.org/10.3322/caac.21166

[22] Maestu, I., Pastor, M., Gómez-Codina, J., et al. (1997) Pretreatment Prognostic Factors for Survival in Small-Cell Lung Cancer: A New Prognostic Index and Validation of Three Known Prognostic Indices on 341 Patients. Annals of Oncology, 8, 547-553. https://doi.org/10.1023/A:1008212826956

[23] Bharti, M.K., Chauhan, A., Kaushal, V., et al. (2011) Characteristics, Treatment Patterns and Outcomes of Patients with Small Cell Lung Cancer. A Retrospective Analysis, 2, 2206-2210.

[24] Tsao, A.S., Liu, D., Lee, J.J., et al. (2006) Smoking Affects Treatment Outcome in Patients with Advanced Non-Small Cell Lung Cancer. Cancer, 106, 2428-2436. https://doi.org/10.1002/cncr.21884

[25] Videtic, G.M., Stitt, L.W., Dar, A.R., et al. (2003) Continued Cigarette Smoking by Patients Receiving Concurrent Chemoradiotherapy for Limited-Stage Small Cell Lung Cancer Is Associated with Decreased Survival. Journal of Clinical Oncology, 21, 1544-1549. https://doi.org/10.1200/JCO.2003.10.089

[26] Govindan, R., Page, N., Morgensztern, D., et al. (2006) Changing Epidemiology of Small-Cell Lung Cancer in the United States over the Last 30 Years: Analysis of the Surveillance, Epidemiology and End Results Database. Journal of Clinical Oncology, 24, 4539-4544. https://doi.org/10.1200/JCO.2005.04.4859

[27] Vallieres, E., Shepherd, F.A., Crowly, J., et al. (2009) International Association for the Study of Lung Cancer International Staging Committee and Participating Institutions. The IASLC Lung Cancer Staging Project: Proposals Regarding the Relevance of TNM in the Pathologic Staging of Small Cell Lung Cancer in the Forthcoming (Seventh) Edition of the TNM Classification of Lung Cancer. Journal of Thoracic Oncology, 4, 1049-1059. https://doi.org/10.1097/JTO.0b013e3181b27799

[28] Luan, Z., Wang, Z., Huang, W., et al. (2015) Efficacy of 3D Conformal Thoracic Radiotherapy for Extensive-Stage Small-Cell Lung Cancer: A Retrospective Study. EXperimental and Therapeutic Medicine, 10, 671-678. https://doi.org/10.3892/etm.2015.2526 
[29] Unalmus, D., Yasar, Z., Buyuksirin, M., et al. (2015) Clinical Features and Outcomes of Patients with Small Cell Lung Carcinoma; Retrospective Analysis. Acta Medica Anatolia, 3, 47-50. https://doi.org/10.15824/actamedica.65675

[30] Hanna, N., Bunn Jr., P.A., Langer, C., et al. (2006) Randomized Phase III Trial Comparing Irinotican/Cisplatin with Etoposide/Cisplatin in Patients with Previously Untreated Extensive-Stage Disease Small-Cell Lung Cancer. Journal of Clinical Oncology, 24, 2038-2043. https://doi.org/10.1200/JCO.2005.04.8595

[31] Frülh, M., De Ruysscher, D., Popat, S., et al. (2013) ESMO Guidelines Working Group: Small-Cell Lung Cancer (SCLC): ESMO Clinical Practice Guidelines for Diagnosis, Treatment and Follow-Up. Annals of Oncology, 24, vi99-vi105.

[32] Noda, K., Nishiwaki, Y., Kawahara, M., et al. (2002) Irinotican plus Cisplatin Compared with Etoposide plus Cisplatin for Extensive Small-Cell Lung Cancer. The New England Journal of Medicine, 346, 85-91. https://doi.org/10.1056/NEJMoa003034

[33] Natale, R.B., Lara, P.N., Chansky, K., et al. (2008) SO124: A Randomized Phase III Trial Comparing Irinotican/Cisplatin (IP) with Etoposide/Cisplatin (EP) in Patients with Previously Untreated Extensive Stage Small Cell Lung Cancer (E-SCLC). Journal of Clinical Oncology, 26, 7512.

https://doi.org/10.1200/jco.2008.26.15_suppl.7512

[34] Lee, J.H., Kim, S.H., Kim, S.Z., et al. (2009) Retrospective Analysis of Chemoradiotherapy for Limited-Stage Small-Cell Lung Cancer. The Journal of the Korean Society for Therapeutic Radiology and Oncology, 27, 133.

https://doi.org/10.3857/jkstro.2009.27.3.133

[35] Nathan, R., Foster, M.S., Sumithera, J., et al. (2009) Prognostic Factors Differ by Tumor Stage for Small Lung Cancer. Cancer, 15, 2721-2731.

[36] Cerny, T., Blair, V., Anderson, H., et al. (1987) Pretreatment Prognostic Factors and Scoring System in 407 Small-Cell Lung Cancer Patients. International Journal of Cancer, 39, 146-149. https://doi.org/10.1002/ijc.2910390204

[37] Souhami, R.L., Bradbury, I., Geddes, D.M., et al. (1985) Prognostic Significance of Laboratory Parameters Measured at Diagnosis in Small Cell Carcinoma of the Lung. Cancer Research, 45, 2878-2882.

[38] Onoda, N., Nehmi, A., Weiner, D., et al. (2001) Nicotine Affects the Signaling of the Death Pathway, Reducing the Response of Head and Neck Cancer Cell Lines to DNA Damaging Agents. Head Neck, 23, 860-870. https://doi.org/10.1002/hed.1125

[39] Dasgupta, P., Kinkade, R., Joshi, B., et al. (2006) Nicoyine Inhibits Apoptosis Induced by Chemotherapeutic Drugs by Up-Regulating XIAP and Surviving. Proceedings of the National Academy of Sciences of the United States, 103, 6332-6337. https://doi.org/10.1073/pnas.0509313103

[40] Heeschen, C., Jang, J.J., Weis, M., et al. (2001) Nicotine Stimulates Angiogenesis and Promotes Tumor Growth and Atherosclerosis. Nature Medicine, 7, 833-839. https://doi.org/10.1038/89961

[41] Mousa, S. and Mousa, S.A. (2006) Cellular and Molecular Mechanisms of Nicotine's Pro Angiogenesis Activity and Its Potential Impact on Cancer. Journal of Cellular Biochemistry, 97, 1370-1378. https://doi.org/10.1002/jcb.20741

[42] Zhang, Q., Tang, X., Zhang, Z.F., et al. (2007) Nicotine Induces Hypoxia-Inducible Factor-1 Alpha Expression in Human Lung Cancer Cells via Nicotine Acetylcholine Receptor-Mediated Signaling Pathways. Clinical Cancer Research, 13, 4686-4694. https://doi.org/10.1158/1078-0432.CCR-06-2898

[43] Chen, J., Jiang, R., Garces, Y.I., et al. (2010) Prognostic Factors for Limited-Stage 
Small Cell Lung Cancer: A Study of 284 Patients. Lung Cancer, 67, 221. https://doi.org/10.1016/j.lungcan.2009.04.006

[44] Bergman, B. and Sorenson, S. (1988) Smoking and Effect of Chemotherapy in Small Cell Lung Cancer. European Respiratory Journal, 1, 932-937.

[45] Kuo, H.Y., Lin, Z.Z., Yang, Y.Y., et al. (2012) Survival of Patients with Small Cell Lung Carcinoma in Taiwan. Oncology, 82, 19-24. https://doi.org/10.1159/000335084

[46] Sculier, J.P., Chansky, K., Crowly, J.J., et al. (2008) The Impact of Additional Prognostic Factors on Survival and Relationship with the Anatomical Extent of Disease Expressed by the $6^{\text {th }}$ Edition of the TNM Classification of Malignant Tumors and the Proposals for the $7^{\text {th }}$ Edition. Journal of Thoracic Oncology, 3, 457-466. https://doi.org/10.1097/JTO.0b013e31816de2b8

[47] Gaspar, L.E., McNamara, E.J., Gay, E.G., et al. (2012) Small Cell Lung Cancer: Prognostic Factors and Changing Treatment over 15 Years. Clinical Lung Cancer, 13, 115-122. https://doi.org/10.1016/j.cllc.2011.05.008

[48] Albain, K.S., Crowley, J.J., LeBlank, M., et al. (1990) Determinants of Improved Outcome in Small Cell Lung Cancer: An Analysis of the 2,580-Patients Southwest Oncology Group Data Base. Journal of Clinical Oncology, 8, 1563-1574. https://doi.org/10.1200/JCO.1990.8.9.1563

[49] Spiegelman, D., Maurer, L.H., Ware, J.H., et al. (1989) Prognostic Factors in Small-Cell Carcinoma of the Lung: An Analysis of 1,521 Patients. Journal of Clinical Oncology, 7, 344-354. https://doi.org/10.1200/JCO.1989.7.3.344

[50] Ramlov, A., Tietze, A., Khalil, A.A., et al. (2012) Prophylactic Cranial Irradiation in Patients with Small Cell Lung Cancer. A Retrospective Study of Recurrence, Survival and Morbidity. Lung Cancer, 77, 561-566.

https://doi.org/10.1016/j.lungcan.2012.05.101

[51] Aynaci, Ö., Canyilmaz, E., Serdar, L., et al. (2016) Survival and Prognostic Factors in Limited Stage Small Cell Lung Cancer: A Retrospective Study from Northeast Turkey. Journal of Cancer Research and Therapeutics, 12, 238-243. https://doi.org/10.4103/0973-1482.151446

[52] Pijls-Johannesma, M., De Ruysscher, D., et al. (2007) Timing of Chest Radiotherapy in Patients with Limited Stage Small Cell Lung Cancer: A Systematic Review and Meta-Analysis of Randomized Controlled Trials. Cancer Treatment Reviews, 33, 461-473. https://doi.org/10.1016/j.ctrv.2007.03.002 